\title{
Recent Advances at NASA in Calculating the Electronic Spectra of Diatomic Molecules
}

Ellis E. Whiting and John A. Paterson

(AASA-IM-101Jj4) BECENI ACVANCES AT NASA IN
CALCUIAIING TEE LLECTECNLC SEFCTEA CF
LATCEIC MCLECULES (NASA) AE F CSCL $22 B$
N $89-12622$

Unclas

0174980

October 1988

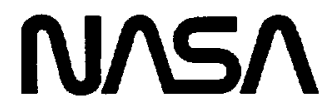

National Aeronautics and

Space Administration 


\section{Recent Advances at NASA in Calculating the Electronic Spectra of Diatomic Molecules}

Ellis E. Whiting, ELORET Institute, Sunnyvale, California John A. Paterson, Ames Research Center, Moffett Field, California

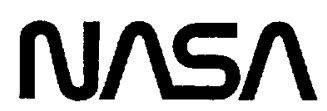

National Aeronautics and

Space Administration 



\title{
RECENT ADVANCES AT NASA IN CALCULATING THE ELECTRONIC SPECTRA OF DIATOMIC MOLECULES
}

\author{
Ellis E. Whiting \\ ELORET Institute, a Sunnyvale, California 94087 \\ John A. Paterson \\ NASA Ames Research Center, Moffett Field, California 94035
}

SUMMARY

Advanced entry vehicles, such as the proposed Aero-assisted Orbital Transfer Vehicle, provide new and challenging problems for spectroscopy. Large portions of the flow field about such vehicles will be characterized by chemical and thermal nonequilibrium. Only by considering the actual overlap of the atomic and rotational lines emitted by the species present can the impact of radiative transport within the flow field be assessed correctly. To help make such an assessment, a new computer program is described that can generate high-resolution, line-by-line spectra for any spin-allowed transitions in diatomic molecules. The program includes the matrix elements for the rotational energy and distortion to fourth order, the spin-orbit, spin-spin, and spin-rotation interactions to first order, and the lambda splitting by a perturbation calculation. An overview of the Computational Chemistry Branch at Ames Research Center is also presented.

\section{INTRODUCTION}

It is indeed a great pleasure for me to be here at Tehany and to participate in this conference dedicated to Professor Kovács. His dedicated and creative research of over 50 years has brought order and clarity to the study of diatomic spectroscopy and has provided us with an incredible array of practical and elegant formulae that enable us to calculate realistic spectra. His work has certainly been the basis for much of my own work. His book (Kovács, 1969) on the "Rotational Structure in the Spectra of Diatomic Molecules" presents the theory in a logical step-by-step way and the results in an easy to use format. Professor Kovács, I am sure that all of us here have been, and will continue to be, influenced greatly by your accomplishments. We thank you very sincerely, and we wish you continued success in your life and research.

I am also pleased to be here as an unofficial representative of NASA. The coming year (1989) after nearly 3 years of pain, soul-searching, and redesign, will see the rebirth of the Shuttle program and at least two launches of great scientific and spectroscopic interest: the placing of the Hubble telescope in Earth orbit and the launch of the Galileo Jupiter-entry mission. The Hubble telescope will see farther back into time than ever before possible, and the Jupiter entry probe will provide direct in situ measurements in the atmosphere of this mysterious giant. We expect the new discoveries made by these missions to greatly increase our understanding of the universe and they will, I am sure, provide a vast array of new puzzles to be solved. Unfortunately, we will need to be very patient for results from the Galileo mission, as the transit time to Jupiter will be approximately 7 long years.

aMailing address: NASA Ames Research Center, Moffett Field, CA 94035. 
The U.S.S.R. is also planning several exciting space launches in 1989 and will land two probes on the surface of the small, 30-km-oblong, Martian moon Phobos. NASA will be cooperating in this mission by providing deep space tracking information to the U.S.S.R. We all hope for world peace, and I believe that the expansion of such cooperative scientific efforts help to achieve our true destiny as one people, one world.

The emphasis of this paper, however, is not on current scientific missions, but instead is focused on some of the ways that spectroscopy will help in building the knowledge base needed to design future advanced atmospheric entry vehicles. A perspective for this work is provided by a brief description of the proposed National Aero-Space Plane (NASP) and the Aero-assisted Orbital Transfer Vehicle (AOTV) concepts and a description of the Aero-assist Flight Experiment (AFE) project. As a part of this perspective, the importance of assessing the impact of radiative transport on an AOTV is described and a new computer program for calculating high-resolution spectra needed for making this assessment is discussed. The last section of the paper highlights the Computational Chemistry Branch at Ames Research Center, and some of its latest results are presented to illustrate the present state of theoretical spectroscopic research.

\section{OVERVIEW OF NASP AND AOTV}

The proposed NASP and AOTV have produced a renaissance in atmospheric entry studies after a hiatus of nearly 15 years. They have reopened old areas of study and placed new demands on the technology base.

An artist's conception of what the NASP might look like is shown in figure 1. The NASP represents an ultimate aero-space plane that would take off from a traditional runway, fly through the atmosphere at high speed, and proceed on into near-Earth space. It is conceived as a possible follow-on to the Shuttle vehicle and would function as a resupply and cargo vehicle for the space station. An alternate version of the NASP may not have a space capability, but instead will function as an intercontinental passenger aircraft, which would fly in the upper reaches of the atmosphere and be able to travel from Los Angeles to Tokyo in about 2 hours.

A possible design of an AOTV is shown in figure 2. This spacecraft is intended to ferry people and cargo between geosynchronous orbit and low Earth orbit or between the moon and low Earth orbit. The payload of an orbital transfer vehicle can be approximately doubled if the Earth's atmosphere, rather than a retrorocket, is used to dissipate the kinetic energy of such a vehicle after it has returned from a high orbit and before it is inserted into a low Earth orbit.

The NASP and AOTV differ from previous entry vehicles, such as Apollo and Space Shuttle, in that they are intended to fly at high altitude and high speed for considerable periods of time. Under these conditions the air flowing around them will be characterized by extensive regions that are not in either chemical or thermal equilibrium, i.e., the collision rate in the reacting flow field is too low to promote equilibrium before the gas flows through a significant portion of the flow field.

One important result of these flight conditions is that the radiative heating of the vehicle will be greatly enhanced. Thus, the design of safe and efficient vehicles requires that the radiative heating from the nonequilibrium flow field around the vehicles be known accurately. This situation provides an important 
impetus to spectroscopic research and to the development of engineering methods based on spectroscopic techniques and results.

Flow-field solutions must be developed that couple fluid mechanics, chemical reactions, other relaxation phenomena, and radiative transport. The radiative portion of the problem requires knowledge of the excitation state, the high-temperature properties, and the spectroscopic parameters of the species present in the flow field, as well as the availability of computational tools necessary to calculate the radiative transport to a high degree of precision.

The technology base necessary to design NASP and AOTV vehicles is being developed. However, because of the increase in knowledge necessary in many scientific and engineering disciplines, it is quite likely that intermediate test vehicles will be flown before an actual vehicle is designed. The NASP program has not yet advanced to the stage of having an approved test vehicle program. The AOTV has reached this stage of development, and the test program is called the Aero-assist Flight Experiment (AFE).

The AFE test vehicle for the AOTV is shown in figure 3 as it might appear as it enters the Earth's atmosphere. A tentative mission profile for the AFE is shown in figure 4. This profile shows the vehicle being launched from the Shuttle, being propelled toward the Earth to simulate return from a geosynchronous orbit, flying through the Earth's upper atmosphere at an altitude of about $70 \mathrm{~km}$, leaving the atmosphere, and being recovered by the Shuttle.

A large amount of high- and low-resolution spectroscopic, pressure, acceleration, and temperature data will be recorded during the flight through the atmosphere. These data will provide a realistic data base for a reasonably large vehicle against which predictions and predictive techniques can be evaluated, and will lead to the development of a more advanced and reliable computational capability. Some important aspects of the AFE project that are directly related to the base of spectroscopic knowledge are discussed in the following section.

\section{AFE AND RADIATIVE TRANSPORT}

The radiometric data taken during the AFE flight is crucial in helping to understand the chemistry and excitation mechanisms taking place in the flow field. Interpreting these data will involve a complex interplay of predictions based on various flow-field, chemical, excitation, and radiation models. The signal recorded by each radiometric instrument will be an integral of all optical effects taking place within the view field and optical bandpass of that instrument. The principal tool for interpreting these data will be the flow-field solution being developed by the people on the project team who are expert in various aspects of computational fluid dynamics.

The accuracy of the flow-field solution will depend upon realistic chemical and excitation models, and upon accurate reaction rates, cross sections, partition functions, transport properties, and transition moments in gases characterized by multiple temperatures, some of which are well above the temperatures at which reliable experimental data are available.

Dr. Chul Park at Ames Research Center, and a member of the AFE team, has developed a twotemperature (TTV) model of the reacting flow and a quasi-steady state (QSS) model of the electronic excitation of the atomic and molecular species in the nonequilibrium flow field. The TTV model equates the kinetic temperature of the atoms and molecules and the rotational temperature. It also equates the vibra- 
tional, electronic excitation and electron kinetic temperatures. The QSS model assumes that the resultant population of an electronic state changes much more slowly than the separate rates for populating and depopulating the state.

The TTv model greatly simplifies the flow-field solution, and the QSS models the calculation of radiative intensities. These models appear to give reasonable results when compared to available experimental data for compressive flow, such as those on the front surface of an entry vehicle, but they may not be valid for the expanding flow from the outer edge of the vehicle into the wake region.

Computer programs for the one-dimensional reacting flow behind a normal shock wave and along the stagnation streamline between a normal shock wave and a blunt body have been written by Dr. Park using the TTV and QSS models. Some sample results generated by the stagnation streamline program for conditions appropriate for the AFE flight trajectory are shown in figure 5. Only a qualitative description of the flow field is given, as all reference to flight and thermodynamic conditions have been removed from the figure.

Figure 5 shows that the heavy-particle kinetic temperature jumps to a high value directly behind the shock wave where the vibrational temperature is still close to the free-stream value. As the flow continues, collisions begin to dissociate the molecules and excite the internal states of the atoms and molecules. These processes lower the heavy-particle kinetic temperature and cause the vibrational temperature to rise. At some point the vibrational temperature reaches a peak value and begins to follow the kinetic temperature as equilibrium is approached. Also, at some point significant numbers of electrons begin to be produced and they play a major role in the electronic excitation process.

The total specific intensity of the gas from 2000 to $10,000 \AA$ is also presented in figure 5 . The specific intensity rises to a peak value and then begins to drop substantially as the flow relaxes toward equilibrium. The large nonequilibrium overshoot in the radiation is due to the high temperatures and the species present in the reacting region of the shock layer. The radiation above $2000 \AA$ is produced primarily by diatomic species that exist in the reacting region, but disappear as equilibrium is approached, under the AFE entry conditions. Below a wavelength of $2000 \AA$ the radiation is produced principally by atomic nitrogen and oxygen.

The radiation emitted by the shock layer alters the energy distribution in the shock layer, heats the vehicle, and produces the signal levels for the radiometric measurements. Thus, the impact of the radiation on the flow field, the vehicle, and the signal levels must be carefully assessed. Under the flight conditions of the AFE trajectory, the radiative heating load is expected to be a significant fraction of the total heat load.

The problem of radiative energy transport is greatly simplified for two special situations: (1) the gas is optically thick so that the photons are absorbed very close to the point where they are emitted and (2) the gas is optically thin so that all photons emitted are lost from the flow field. In the case of an optically thick gas, neither significant energy redistribution nor radiative transport occurs. In the case of an optically thin gas, the radiation acts as a simple energy sink at each point in space, and vehicle heating can be calculated in a straightforward manner by line-of-sight methods.

If the flow field on the AFE does not fall into either of these simple cases, then the very difficult general radiative transport problem, which couples each point in the flow field to all other points, must be solved or adequately approximated. 
The absorption coefficient of the gas in the flow field gives a qualitative assessment of the importance of radiative transport on the flow-field solution and the radiative heating of the vehicle. Figure 6 shows the calculated absorption coefficient for the spectral region from about 1100 to $3400 \AA$, at a point on the stagnation streamline shown in figure 5 , near the peak of the specific intensity curve. The absorption coefficient at longer wavelengths does not change the conclusions that follow. The line width used in these calculations was $5 \AA$ in order to cover a wide wavelength range. The actual line width, however, is about $0.05 \AA$. Thus, peak absorption coefficient values shown here must be increased by about a factor of 100 to correspond to the actual peak absorption coefficients.

Multiplying the values plotted in figure 6 by 100 still leaves the maximum absorption coefficients in the region above $2000 \AA$ less than $0.01 \mathrm{~cm}^{-1}$. This value indicates that the flow field above $2000 \AA$ is expected to be nearly optically thin, as the shock layer thickness is only about $15 \mathrm{~cm}$.

The calculated absorption coefficients shown here below $2000 \AA$ are produced principally by atomic lines with a background of free-bound and free-free transitions. Across each atomic line the absorption coefficient varies by several orders of magnitude. Near the line center where the radiation is most intense the absorption coefficients, after again being multiplied by a factor of 100 , are about $10.0 \mathrm{~cm}^{-1}$ or greater. This calculation indicates that below $2000 \AA$ the gas is probably optically thick. The radiation emitted in this spectral region, however, is so intense that even if only a small fraction of it reaches the vehicle surface, it could produce a significant contribution to the total heat load. Therefore, the radiative transport in this region of the spectrum must be examined in far greater detail to assess the importance of radiative transfer on vehicle heating and on the energy redistribution in the shock layer.

Future radiative transport calculations will be improved in two important ways: (1) by including the $\mathrm{N}_{2}$ band systems that transition to the ground state and emit significant radiation, and (2) by using more accurate, higher-resolution spectral calculations. Most of the important $\mathrm{N}_{2}$ band systems that transition to the ground state are shown in figure 7. Two of these systems, the first and second Birge-Hopfield systems, are allowed transitions and will be included in future calculations. In addition, some of the stronger forbidden transitions may also be included, such as the Vegard-Kaplan and Lyman-Birge-Hopfield systems.

The inclusion of these $\mathrm{N}_{2}$ band systems will increase the specific intensity emitted by the gas below $2000 \AA$. However, because they involve the ground state of the $\mathrm{N}_{2}$ molecule and because the $\mathrm{N}_{2}$ concentration is always fairly high under AFE flight conditions, it is expected that their contributions to the absorption coefficient will be large and that they will cause the radiative transport to decrease.

By using more realistic line shapes and an improved method of calculating the wavelengths of rotational lines, the radiative transport calculations will be improved by increasing the spectral resolution. High-resolution calculations are necessary to ensure that the actual overlap of rotational and atomic lines occurring in the flow field is handled correctly. The line width and shape under the AFE flight conditions are determined principally by Doppler broadening. However, a range of line shapes, including some with strong wings, will be explored to determine the sensitivity of the calculations to this parameter.

Accurate energy levels, or, equivalently, wavelengths or wavenumbers, will be calculated by direct diagonalization of the Hamiltonian matrices for the upper and lower states. The computer program developed to make these calculations at high spectral resolution is discussed in the following section. 


\section{COMPUTER PROGRAM FOR HIGH-RESOLUTION SPECTRAL CALCULATIONS}

The computer program for calculating high-resolution spectra is based on direct diagonalization of the Hamiltonian matrix, which includes the matrix elements shown in figure 8. The matrix elements included are those for the rotational energy and rotational distortion up to fourth order and first-order spin-orbit; spin-spin, and spin-rotation interactions. The expressions shown are derived in Kovács (1969), except for the $\mathrm{Hv}$ and Fv rotational terms. The general form of the rotational terms is given by Murai and Shimauchi (1966). The spin-spin interaction between the lambda components of ${ }^{3} \Pi_{0}$ substates has not been included in the Hamiltonian matrix, but is included indirectly in the perturbation calculation of the lambda splitting, to be discussed later.

The Hamiltonian matrix is developed for a single electronic state in Hund's case(a) basis functions. That is, both $\Lambda$ and $\Sigma$ are defined in the basis set, which is a realistic basis for the nonrotating molecule. The transition from Hund's case(a) to case(b) as molecular rotation increases is produced by the off-diagonal terms in the Hamiltonian matrix. Diagonalization of the Hamiltonian matrix gives the energy levels and the proper mix of the basis functions that defines the corresponding wave functions.

Lambda splitting of the energy levels is included in the analysis as a perturbation calculation, as shown in figure 9. This calculation provides an estimate of the actual lambda splitting without having to build a Hamiltonian matrix that involves several electronic states. The calculation uses the matrix $\mathrm{S}$ that diagonalizes the Hamiltonian matrix and the parameters $C_{0}, C_{1}, C_{2}$, and $C_{3}$ that are usually determined experimentally. The expression for the lambda splitting of triplet states is given here, which is taken from Dixon (1959). Kovács (1969) contains this expression without the $C_{3}$ term, and similar expressions for the singlet, doublet, and quartet cases.

The new computer program includes the Hamiltonian matrix as outlined above, the program by Whiting (1973) to calculate the rotational line intensity factors of diatomic molecules, and the program by Whiting, Arnold, and Lyle (1969) to generate a line-by-line spectrum for atoms and diatomic molecules. The new program accurately calculates wavelengths and intensity factors for any spin-allowed transition, generates a synthetic spectrum to high resolution, and plots the resultant spectrum. The extension to the spin-forbidden case should be straightforward with due consideration to the cases in which the lambda components are not of equal intensity.

The new program was tested by calculating the high-resolution spectrum of the $(0,0)$ band of the $A^{3} \Pi \rightarrow X^{3} \Sigma^{-}$transition of the NH molecule and comparing the calculated wavenumbers for the rotational lines with the experimental data of Funke (1935 and 1936) and Dixon (1959). The difference between the calculated and experimental values is shown in figure 10 for the $P_{1}$ branch. The cutoff in the spectrum at a rotational number of about 34 is due to rotational dissociation in the upper state.

The calculated results were made using the spectroscopic parameters determined by Dixon (1959), Murai and Shimauchi (1966), and the present work. Notice the large change in scale for the y-axis when using Dixon's parameters. For high rotational values the calculated results of both Murai and Shimauchi and the present work deviate from the experimental data. This is due to the contributions of the higherorder rotational constants (Hv and $\mathrm{Fv}$ ) and lambda splitting parameters $\left(\mathrm{C}_{2}\right.$ and $\mathrm{C}_{3}$ ), which are each quite large, about 15 to $20 \mathrm{~cm}^{-1}$. Slight changes in these parameters can produce improved agreement in any selected branch, but they degrade the agreement between theory and experiment in at least some of the other branches. Generally, the agreement between the calculated and experimental values is good when using the parameters determined by Murai and Shimauchi and by the present work. 
The parameters used in the calculations are shown in Table I. Dixon's values were based on the rotational distortion produced only by the diagonal Dv matrix elements. Murai and Shimauchi determined improved rotational constants, and in the present work we have made slight adjustments to the combined parameters of Dixon and Murai and Shimauchi. Veseth (1972) also analyzed this transition, and his parameters are shown in Table I. His parameters, however, were determined using a more complete Hamiltonian matrix which included both the $\mathrm{A}^{3} \Pi$ and $\mathrm{X}^{3} \Sigma^{-}$- states simultaneously. Thus, his "true" parameters are not appropriate for the single-state Hamiltonian matrix used here, and also used by Dixon and Murai and Shimauchi. Introducing his parameters into the present program produces an error of about $25 \mathrm{~cm}^{-1}$ at $\mathrm{N}^{\prime}$ values near 30 . The single-state parameters are considered to be "effective" parameters.

Three plots of the $(0,0) \mathrm{NH}$ band generated using the parameters from the present work are shown in figure 11. All 27 branches are included in these plots, and some of the weak satellite branches can be seen in the logarithmic plots.

The new program provides a powerful computational tool for generating high-resolution spectra for any allowed transition and will be used to help understand the radiative transport in the AFE flow field from 1000 to $2000 \AA$. However, spectral programs such as this one still depend on the availability of accurate spectroscopic parameters (e.g., the parameters discussed above for the energy levels and those needed for absolute intensity calculations, such as the transition moments).

Previously, most spectroscopic parameters have come principally from experimental measurements. However, a revolution in spectroscopy has occurred in the past 5 to 10 years and now many of these parameters are calculated to high accuracy by theoretical methods. The reasons for this change have been the development of high-speed, large-memory supercomputers and the highly sophisticated computer programs for solving the Schrödinger equation for diatomic and triatomic molecules. One of the groups that make such calculations is the Computational Chemistry Branch at Ames Research Center. This group and some of its results are highlighted in the following section.

\section{COMPUTATIONAL CHEMISTRY AT AMES RESEARCH CENTER}

The research effort in computational chemistry at Ames Research Center was initiated in 1973 and was organized as a separate research branch in 1985. This work continues to receive strong management support because the research closely supports the Center's major thrust in computational fluid dynamics, particularly at high temperatures, and because of its unique scientific capability within NASA. The Computational Chemistry Branch is a major user of the computational resources at the center. These resources include a Cray X-MP in the Center's central computer facility and two Cray-2s in the Numerical Aerodynamic Simulation (NAS) facility, which is a national facility for research in computational fluid dynamics located at Ames.

The Computational Chemistry Branch carries out research in the two broad discipline areas shown in Table II. These areas are gas-phase and gas-surface interactions. The gas-phase work is further subdivided into molecular properties; reaction rates and scattering, and transport properties and cross sections. The gas-surface work is subdivided into metallic and polymer surfaces. For each of these subdisciplines, selected molecular systems or reactions that have been studied recently are listed to illustrate the broad range of topics covered. Some of the work listed has not yet appeared in the literature. 
A detailed study of the accuracy of the molecular properties calculated, based on the approximations used, has been made by the Ames researchers. The problem of which configurations to include in the calculation (the correlation problem) can now be examined in depth because the Cray-2 memory permits full configuration interaction ( $\mathrm{CI}$ ), benchmark calculations to be made. For example, a full $\mathrm{Cl}$ calculation on the $\mathrm{H}_{2} \mathrm{O}$ molecule made by Bauschlicher and Taylor (1986), included 28 million determinants and 7 million configurations, which required about 70 million words of fast memory. This calculation required about 10 hours of CPU time. Such benchmark calculations enable the results from approximate methods to be evaluated. Some are found to give very reliable results and also reduce the CPU time required to less than $0.1 \%$ of that required for a full CI calculation.

The full $\mathrm{CI}$ benchmark calculations have also clearly identified limitations in previous basis sets and have led to the development of improved basis sets based on atomic natural orbitals. These new basis sets lead to results that are superior to any previous set and also markedly reduce the computer time required.

The techniques discussed above were used by Bauschlicher et al. (1987) and Bauschlicher and Langhoff (1987) to identify the ground states of $\mathrm{Al}_{2}$, and $\mathrm{Si}_{2}$, even though the separation between the two lowest states for these molecules is less than $300 \mathrm{~cm}^{-1}$. These calculations were made in a two-step process. A full $\mathrm{CI}$ calculation was made in a small basis set to confirm the reliability of the approximate treatment, and then the approximate treatment was carried out in an expanded atomic natural orbital basis to give accurate results.

The calculation of reaction rates requires considerable more time than that for the properties of isolated diatomic molecules. For example, it takes about 50 hours of Cray- 2 time to calculate the reaction rate for the relatively simple $\mathrm{N}+\mathrm{O}_{2} \rightarrow \mathrm{NO}+\mathrm{O}$ reaction to an accuracy of about $10 \%$, Jaffe, Pattengill, and Schwenke (1988). The 50 hours breaks down to about 49 hours to generate the potential surface of the $\mathrm{N}-\mathrm{N}-\mathrm{O}$ complex and about 1 hour to perform several thousand trajectory calculations on the surface to give reasonable reaction statistics. Of course, this does not count the large number of person-hours required to make an analytic fit to the potential surface before the trajectory calculations can be made (Walch and Jaffe, 1987). Fitting the potential surface with analytic functions is one of the most difficult parts of the reactionrate problem and requires considerable skill and ingenuity.

The quality of the spectroscopic results obtainable is demonstrated by the recent publication of the quintet states of $\mathrm{N}_{2}$ by Partridge et al. (1988). Their paper also indicates the way computational research can augment and complement experimental research. A portion of their work on the quintet states is included here to illustrate these points.

The lower electronic states of $\mathrm{N}_{2}$ are shown in figure 12, which was taken from the paper by Partridge et al. (1988). Here the energy of the states is shown as a function of the internuclear distance in Bohr radii. Note that the curve for the $\mathrm{X}^{1} \Sigma_{\mathrm{g}}^{+}$ground state extends $50,000 \mathrm{~cm}^{-1}$ below the bottom of the figure. The quintet states calculated by Partridge et. al. are shown with the closely spaced vibrational levels. The $\mathrm{A}^{\prime} 5 \Sigma_{\mathrm{g}}^{+}$state dissociates to ground state ${ }^{4} S$ nitrogen atoms, and the $C^{\prime \prime} 5 \Pi_{\mathrm{u}}$ state dissociates to ${ }^{4} S$ and ${ }^{2} \mathrm{D}$ nitrogen atoms.

The existence of these quintet states has been discussed in the literature for many years. However, the only experimental evidence for the $\mathrm{A}^{\prime} 5 \Sigma_{\mathrm{g}}^{+}$state is from the predissociation it induces in the $\mathrm{B}^{3} \Pi_{\mathrm{g}}$ and $\mathrm{a}^{1} \Pi_{\mathrm{g}}$ states (Douglas and Herzberg, 1951, and Lofthus and Krupenie, 1977) and for the $C^{\prime \prime} 5 \Pi_{\mathrm{u}}$ state is the predissociation it induces in the $C^{3} \Pi_{u}$ state (Carroll and Mulliken, 1965). All previous theoretical calculations of these states gave shallow potential wells with only one or two vibrational levels in the $\mathrm{A}^{\prime}$ state and less than half the well depth of the $\mathrm{C}^{\prime \prime}$ state shown here. 
The new potential curves for the quintet states calculated by Partridge et al. correctly account for the observed predissociation data and provide much new information about the complex intersystem interactions that occur among the $\mathrm{N}_{2}$ states. Further, they identify for the first time the states involved in the Hermann Infrared band system.

The Hermann Infrared bands were first observed by Hermann (1951) by a low current discharge in $\mathrm{N}_{2}$ at liquid nitrogen temperature. Carroll and Sayers (1953) determined that the bands were formed either by a triplet or a quintet transition. A comparison of the band positions and relative intensities (as calculated by Partridge et al.) with the experimental values is shown in Table III. The comparison is remarkable and demonstrates conclusively that the Hermann Infrared system is produced by the $C^{\prime \prime} 5 \prod_{u} \rightarrow A^{\prime} 5 \Sigma_{s}^{+}$ transition. Their work also shows that this transition does not account for the expected very short lifetime of the C" state, and thus the main pathway for deexcitation of this state remains unknown.

The identification of the Hermann Infrared system is only one of several puzzles concerning $\mathrm{N}_{2}$ that this work has helped to understand. Perhaps the most sophisticated explanation given is for the evidence that the $\mathrm{A}^{\prime} 5 \Sigma_{\mathrm{g}}^{+}$state is a precursor state for populating the $\mathrm{B}^{3} \Pi_{\mathrm{g}}$ state during the recombination of ground-state nitrogen atoms.

The paper by Partridge et al. is a superb example of theoretical spectroscopic analysis. It also provides guidance for future experimental work, such as possible absorption measurements on the Hermann Infrared bands which might identify the principal pathway for deexcitation of the $C^{\prime \prime} 5 \Pi_{\mathrm{u}}$ state and more fully explain the combined roles of both the $\mathrm{A}^{\prime} 5 \Sigma_{\mathrm{g}}^{+}$and $\mathrm{A}^{3} \Sigma_{\mathrm{u}}^{+}$states in the recombination of ground state nitrogen atoms.

\section{CONCLUDING REMARKS}

The proposed development of advanced entry vehicles, such as the National Aero-Space Plane and Aero-assisted Orbital Transfer Vehicle, provides new and challenging problems to be studied and understood. Many of these problems are related to the likelihood that large portions of the flow field around such vehicles will be characterized by chemical and thermal nonequilibrium.

Further, the radiative heating will be enhanced significantly by nonequilibrium effects and can be a significant portion of the total heating load. In particular, a detailed study of the radiative transport in the vacuum ultraviolet region between 1000 and $2000 \AA$ is necessary to assess the impact of radiative transport on the flow-field solution and the vehicle heating. Such a study must be done at high spectral resolution so that the overlap of atomic and molecular rotational lines is handled correctly. The computational tools necessary for such a study have been developed.

The solution of many of the problems encountered in atmospheric entry have been, and will continue to be, found in the application of spectroscopic techniques and results. The Computational Chemistry Branch at Ames Research Center is helping to build the base of needed spectroscopic knowledge and is making important contributions to the understanding of molecular properties and processes by computational methods.

In closing, we express our thanks to the Hungarian Academy of Science for sponsoring this conference and honoring our colleague, friend, and teacher, Professor Kovács. 


\section{REFERENCES}

1. Bauschlicher, C. W., Jr.; and Taylor, P. R.: Benchmark Full Configuration-Interaction Calculations on $\mathrm{H}_{2} \mathrm{O}, \mathrm{F}$ and $\mathrm{F}^{-}$. J. Chem. Phys., vol. 85, 2779 (1986).

2. Bauschlicher, C. W., Jr.; Partridge, H. III; Langhoff, S. R.; Taylor, P. R.; and Walch, S. P.: Accurate ab initio Calculations which Demonstrate a ${ }^{3} \prod_{u}$ Ground State for $\mathrm{Al}_{2}$. J. Chem. Phys., vol. 86, 7007 (1987).

3. Bauschlicher, C. W., Jr.; and Langhoff, S. R.: Ab initio Calculations on $\mathrm{C}_{2}, \mathrm{Si}_{2}$, and SiC. J. Chem. Phys., vol. 87, 2919 (1987).

4. Carroll, P. K.; and Sayers, N. P.: Proc. Phys. Soc., London. Sect. A, vol. 66, 1138 (1953).

5. Carroll, P. K.; and Mulliken, R. S.: J. Chem. Phys., vol. 43, 2170 (1965).

6. Dixon, R. N.: The 0-0 and 1-1 Bands of the $\mathrm{A}\left({ }^{3} \Pi_{i}\right)-\mathrm{X}\left({ }^{3} \Sigma^{-}\right)$System of NH. Can. J. Phys., vol. 37, 1171 (1959).

7. Douglas, A. E.; and Herzberg, G.: Can. J. Phys., vol. 29, 294 (1951).

8. Funke, G.: Z. Physik, vol. 96, 787 (1935).

9. Funke, G.: Z. Physik, vol. 101, 104 (1936).

10. Hermann, R.: C. R. Acad. Sci. (Paris), vol. 233, 738 (1951).

11. Jaffe, R. L.; Pattengill, M. D.; and Schwenke, D. W.: Classical Trajectory Studies of Gas Phase Reaction Dynamics and Kinetics Using Ab Initio Potential Energy Surfaces, to be published in proceedings of the NATO Advanced Research Workshop on Supercomputer Algorithms for Reactivity, Dynamics, and Kinetics of Small Molecules, 1988 (NATO ASI Series, Reidel, Dordrecht).

12. Kovács, I.: Rotational Structure in the Spectra of Diatomic Molecules. Adam Hilger Ltd., London (1969).

13. Lofthus, A.; and Krupenie, P. H.: J. Phys. Chem. Ref. Data, vol. 6, 113 (1977).

14. Murai, T.; and Shimauchi, M.: Rotational Distortions of ${ }^{3} \Pi$ States Applied to NH Molecule. Science of Light, vol. 15, 48 (1966).

15. Partridge, H. III; Langhoff, S. R.; and Bauschlicher, C. W., Jr.: Theoretical Study of the $A^{\prime} 5 \Sigma_{\mathbf{g}}^{+}$ and $C^{\prime \prime} 5 \prod_{\mathrm{u}}$ States of $\mathrm{N}_{2}$ : Implications for the $\mathrm{N}_{2}$ Afterglow. J. Chem. Phys., vol. 88, 3174 (1988).

16. Veseth, L.: Fine Structure of ${ }^{3} \Pi$ and ${ }^{3} \Sigma$ - States in Diatomic Molecules. J. Phys. B: Atom. Molec. Phys., vol. 5, 229 (1972). 
17. Walch, S. P.; and Jaffe, R. L.: Calculated Potential Surfaces for the Reactions: $\mathrm{O}+\mathrm{N}_{2} \rightarrow \mathrm{NO}+\mathrm{N}$ and $\mathrm{N}+\mathrm{O}_{2} \longrightarrow \mathrm{NO}+\mathrm{O}$. J. Chem. Phys., vol. 86, 6946 (1987).

18. Whiting, E. E.; Arnold, J. O.; and Lyle, G. C.: A Computer Program for a Line-by-Line Calculation of Spectra from Diatomic Molecules and Atoms Assuming a Voight Line Profile, NASA TN D5088 (1969).

19. Whiting, E. E.: Computer Program for Determining Rotational Line Intensity Factors for Diatomic Molecules. NASA TN D-7268 (1973). 
TABLE I. - SPECTROSCOPIC PARAMETERS FOR NH $A^{3} \Pi \rightarrow X^{3} \Sigma^{-}$-TRANSITION USED IN CALCULATIONS SHOWN IN FIGURES 10 AND 11 , VALUES $I N \mathrm{~cm}^{-1}$

\begin{tabular}{|c|c|c|c|c|}
\hline \multicolumn{5}{|c|}{$A^{3} \Pi$ STATE } \\
\hline Parameter & Dixon (1966) & Murai and Shimauchi (1966) & Veseth (1972) & Present \\
\hline $\mathrm{B}_{0}$ & 16.3221 & 16.3181 & 16.3018 & 16.3181 \\
\hline$D_{0}$ & $17.58 \times 10^{-4}$ & $17.78 \times 10^{-4}$ & $17.80 \times 10^{-4}$ & $17.78 \times 10^{-4}$ \\
\hline$H_{0}$ & - & $7.80 \times 10^{-8}$ & $9.9 \times 10^{-8}$ & $7.80 \times 10^{-8}$ \\
\hline$F_{0}$ & - & - & $-13.0 \times 10^{-12}$ & $-1.30 \times 10^{-12}$ \\
\hline$A$ & -35.02 & Dixon & -34.79 & $-34.72 .007 \mathrm{~J}(\mathrm{~J}+1)$ \\
\hline$\varepsilon$ & - & - & -0.149 & 0. \\
\hline$\because$ & 0.04 & Dixon & 0.0063 & 0.04 \\
\hline$c_{0}$ & -2.63 & Dixon & Dixon & -2.75 \\
\hline$c_{1}$ & -0.005 & Dixon & Dixon & -0.005 \\
\hline$c_{2}$ & 0.0318 & Dixon & Dixon & 0.0318 \\
\hline$c_{3}$ & $-1.30 \times 10^{-5}$ & Dixon & Dixon & $-1.30 \times 10^{-5}$ \\
\hline \multicolumn{5}{|c|}{$A^{3} \Sigma^{-}$STATE } \\
\hline$B_{0}$ & 16.3454 & 16.3447 & 16.3748 & 16.3447 \\
\hline$D_{0}$ & $16.85 \times 10^{-4}$ & $16.99 \times 10^{-4}$ & $17.097 \times 10^{-4}$ & $16.99 \times 10^{-4}$ \\
\hline$H_{0}$ & - & $10.48 \times 10^{-8}$ & $10.47 \times 10^{-8}$ & $10.48 \times 10^{-8}$ \\
\hline $\mathbf{F}_{0}$ & - & - & $-7.0 \times 10^{-12}$ & 0. \\
\hline$\varepsilon$ & 0.618 & Dixon & 0.557 & 0.618 \\
\hline$\gamma$ & -0.053 & Dixon & -0.0114 & -0.053 \\
\hline Band Origin & 29777.09 & - & - & 29777.50 \\
\hline
\end{tabular}




\section{TAB̈LE II.- COMPUTATIONAL CHEMISTRY BRANCH AT AMES RESEARCH CENTER WTTH SELECTED SYSTEMS THAT HAVE BEEN EXAMINED RECENTLY}

Gas Phase

1. Atomic and Molecular Properties

$\begin{array}{llll}\mathrm{N}_{2}^{+} & \mathrm{H}_{2} \mathrm{O} & \mathrm{N}_{i} \mathrm{~N}_{2} & \mathrm{Si}_{2} \\ \mathrm{NC}_{i} & \mathrm{Al}_{2} & \mathrm{~N}_{i}\left(\mathrm{~N}_{2}\right)_{4} & \mathrm{FeH} \\ \mathrm{OH} & \mathrm{AlC} & \mathrm{N}_{i} \mathrm{CO} & \mathrm{Cu}_{2} \\ \mathrm{~N}_{2} & \mathrm{AlH} & \mathrm{N}_{i}(\mathrm{CO})_{4} & \mathrm{Cu}_{3} \\ \mathrm{CN} & \mathrm{AlN} & \mathrm{F} & \mathrm{F}^{-}\end{array}$

2. Reaction Rates and Scattering

$$
\begin{array}{ll}
\mathrm{Ca}+\mathrm{HF} & \rightarrow \mathrm{CaF}+\mathrm{H} \\
\mathrm{N}+\mathrm{O}_{2} & \rightarrow \mathrm{NO}+\mathrm{O} \\
\mathrm{O}+\mathrm{N}_{2} & \rightarrow \mathrm{NO}+\mathrm{O} \\
\mathrm{H}_{2}+\mathrm{H}+\mathrm{H} & \rightarrow \mathrm{H}_{2}+\mathrm{H}_{2} \\
\mathrm{e}+\mathrm{N}_{2}(v) & \rightarrow e+\mathrm{N}_{2}^{\left(v^{*}\right)} \\
\mathrm{e}+\mathrm{N}_{2}\left(\mathrm{X}^{1} \Sigma_{g}^{+}\right) & \rightarrow e+\mathrm{N}_{2}\left(B^{3} \Pi_{g^{\prime}} A^{3} \Sigma_{u^{\prime}}^{+} w^{3} \Delta_{u^{\prime}} a^{1} \Pi_{g}\right) \\
\mathrm{N}_{2}(v)+\mathrm{N}_{2}\left(v^{\prime}\right) & \rightarrow \mathrm{N}_{2}\left(v^{*}\right)^{2}+\mathrm{N}+\mathrm{N} \\
& \rightarrow \mathrm{N}_{2}\left(v^{*}\right)+\mathrm{N}_{2}\left(v^{\prime *}\right)
\end{array}
$$

3. Transport Properties and Cross Sections
Gas - Surface Interactions

1. Metallic Surface

$$
\begin{aligned}
& \mathrm{Be}_{13} \quad \mathrm{Be}_{55} \\
& \text { Small Al Clusters } \\
& \left(\mathrm{C}_{5} \mathrm{H}_{5} \mathrm{~V}\right)_{2} \mathrm{C}_{8} \mathrm{H}_{8}
\end{aligned}
$$

2. Polymer Surface

Polycarbonate (100,000 segments)

Polyethyiene

Polyimide

$\left.\mathrm{O}\left({ }^{3} \mathrm{P}\right)+\mathrm{C}_{3} \mathrm{H}_{8} \rightarrow \mathrm{C}_{3} \mathrm{H}_{8} \mathrm{O}^{\circ} \rightarrow \mathrm{C}_{3} \mathrm{H}_{7}+\mathrm{OH}^{(2}{ }_{\mathrm{C}}\right)$

$$
\begin{aligned}
& N^{+}-N \\
& O^{+}-O \\
& N-O \\
& \text { Air }
\end{aligned}
$$


TABLE III.- BAND POSITIONS AND RELATIVE INTENSITIES OF THE HERMANN INFRARED SYSTEM TAKEN FROM PARTRIDGE ET AL. (1988)

\begin{tabular}{|c|c|c|c|c|}
\hline & \multicolumn{2}{|c|}{ BAND FOSITIONS (nm) } & \multicolumn{3}{c|}{ RELATIVE INTENSITIES } \\
\cline { 2 - 5 } BAND & THEORY & EXPERIMENT & THEORY & EXPERIMENT \\
\hline 0.0 & $806^{\mathrm{a}}$ & 806 & 3.5 & 4.0 \\
0.1 & 855 & 855 & $1.0^{\mathrm{b}}$ & 1.0 \\
0.2 & 907 & 907 & 0.6 & \\
0.3 & 961 & 963 & 0.3 & \\
0.4 & 1016 & 1023 & 0.1 & \\
1.0 & 753 & 752 & $6.0^{\mathrm{b}}$ & 6.0 \\
1.1 & 795 & 795 & 0.2 & \\
1.2 & 840 & 840 & 0.7 & $<0.5$ \\
1.3 & 886 & 887 & 1.6 & \\
1.4 & 933 & 938 & 1.4 & \\
2.0 & 708 & 706 & $10.0^{\mathrm{b}}$ & 10.0 \\
2.1 & 745 & 744 & 8.8 & 8.0 \\
2.2 & 783 & 783 & 6.6 & 5.0 \\
2.3 & 824 & 824 & 0.3 & $<0.5$ \\
2.4 & 864 & 868 & 0.7 & \\
3.0 & 668 & 667 & $1.5^{\mathrm{b}}$ & 1.5 \\
3.1 & 701 & 700 & 10.4 & 9.0 \\
3.2 & 736 & 735 & 0.6 & $<0.5$ \\
3.3 & 771 & 771 & 4.8 & 3.0 \\
3.4 & 806 & 809 & 2.5 & \\
\hline
\end{tabular}

a THE O-O BANDS WERE SHIFTED INTO COINCIDENCE; THIS REQUIRED A SHIFT OF $559 \mathrm{~cm}^{-1}$ IN THE THEORETICAL $T_{8}$.

b THESE BANDS WERE NORMALIZED TO EXPERIMENT BY ADJUSTING THE VIBRATIONAL POPULATIONS. THIS REQUIRES THAT THE RELATIVE POPULATIONS OF $v^{\prime}=0.3$ BE $0.073,0.295,1.00$, AND 0.725, RESPECTIVELY. 


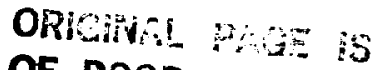 \\ OF POOR QUALITY}

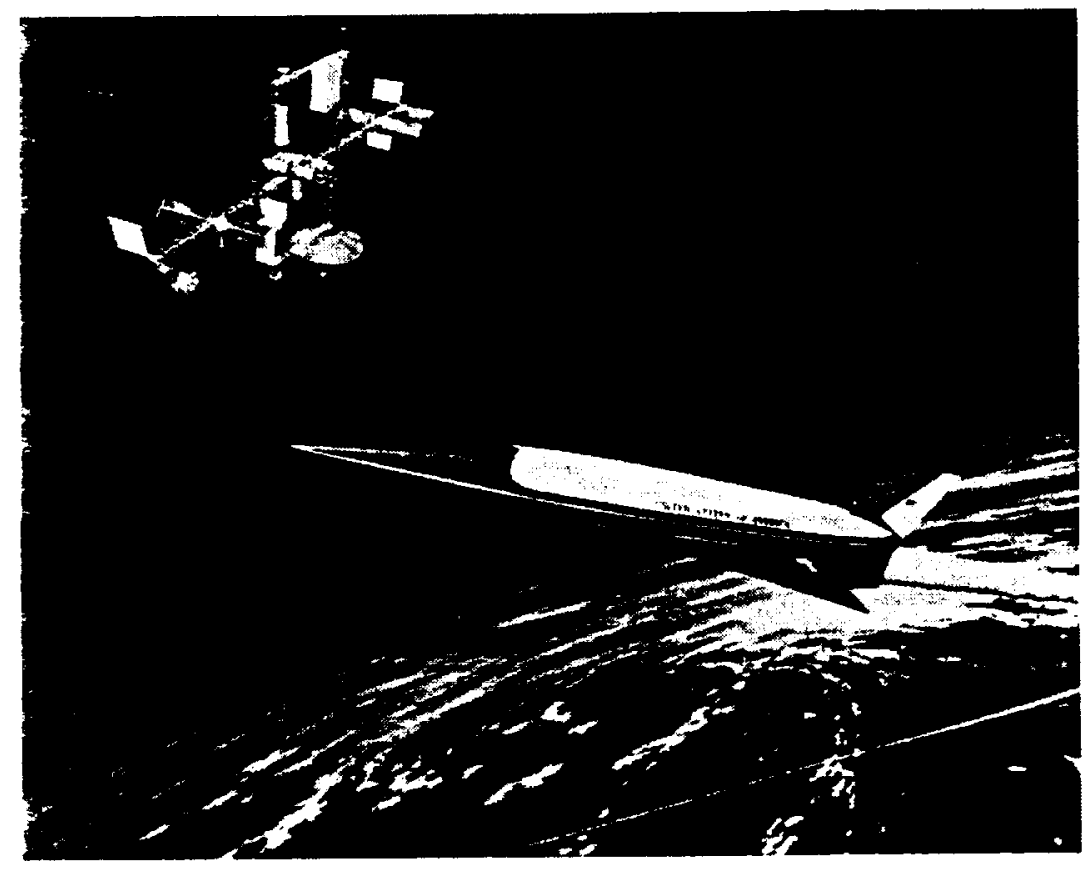

Figure 1.- Artist's conception of National Aero-Space Plane (NASP).

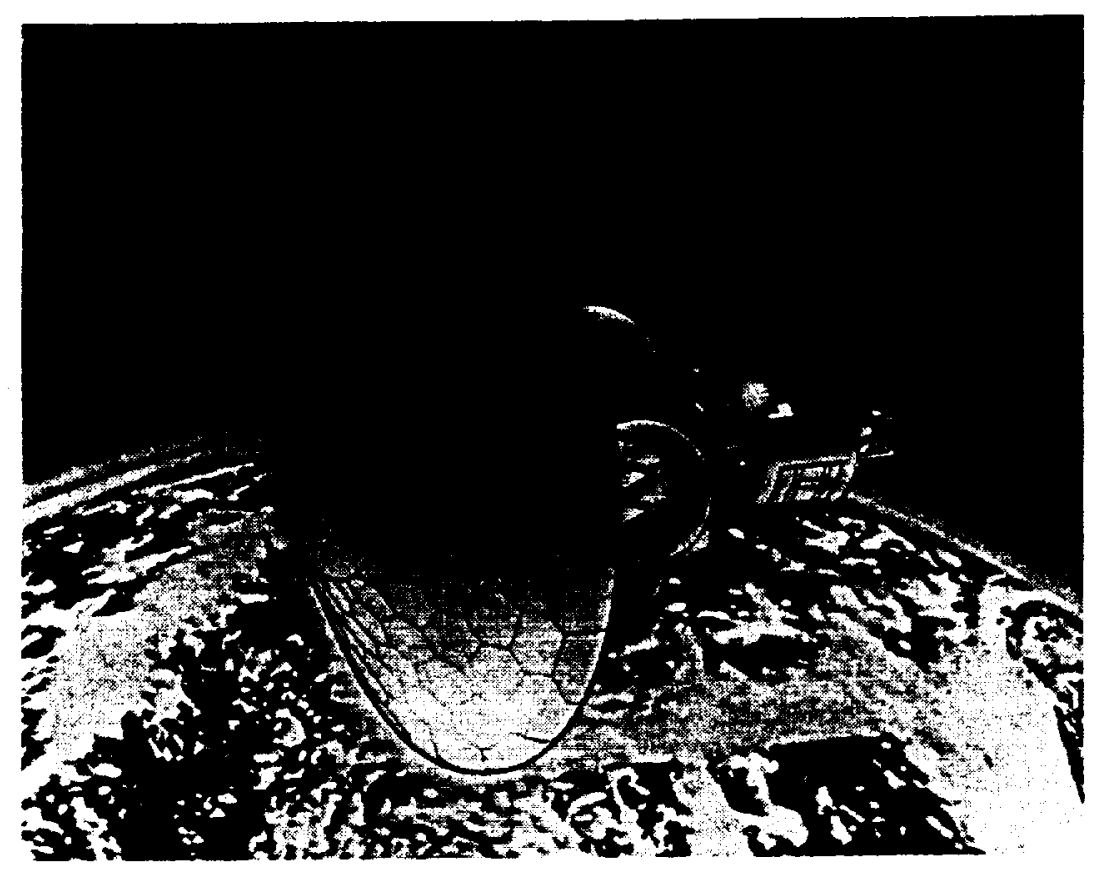

Figure 2.- Artist's conception of a possible design for the Aero-assisted Orbital Transfer Vehicle (AOTV). 


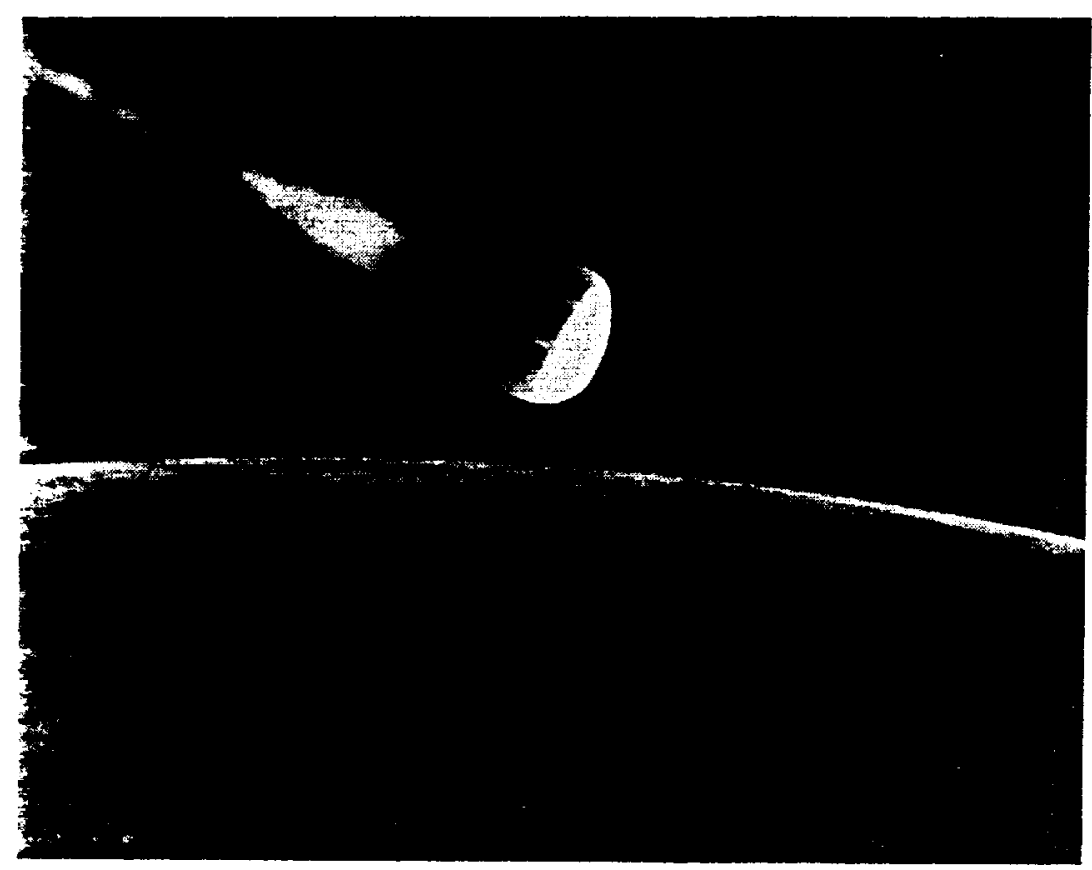

Figure 3.- Aero-assist Flight Experiment (AFE) vehicle as it enters the Earth's atmosphere.

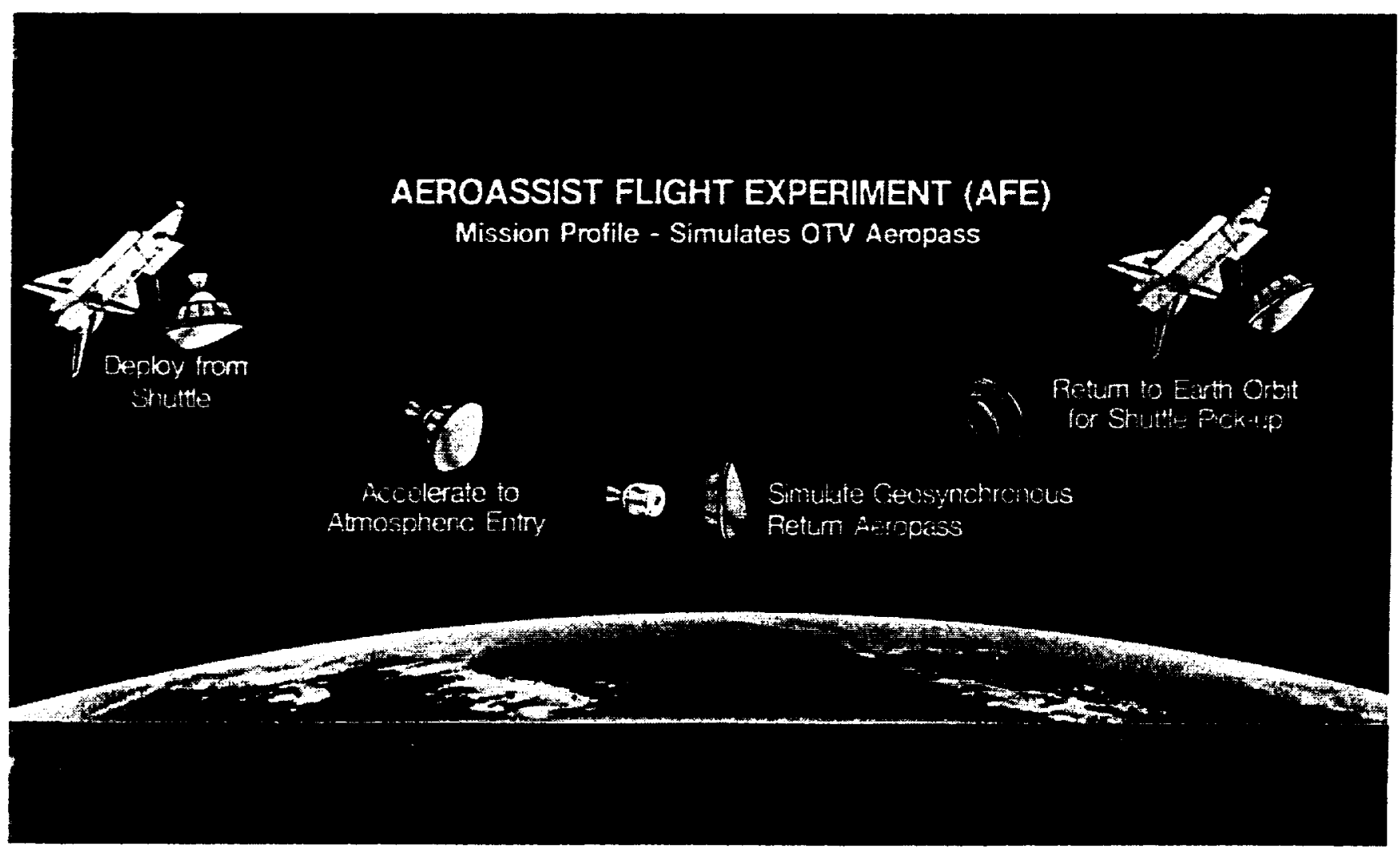

Figure 4.- A tentative mission profile for the AFE. 


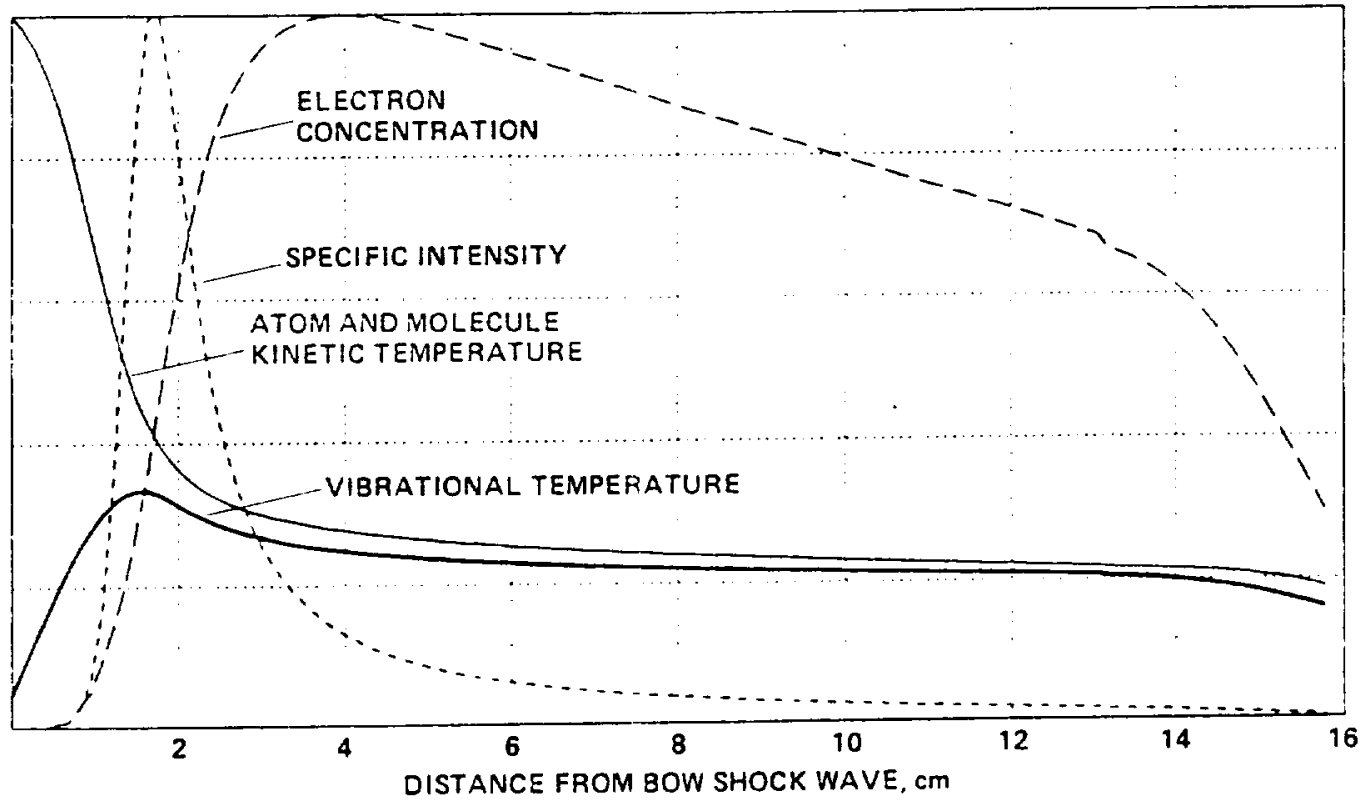

Figure 5.- Flow-field properties along AFE stagnation streamline near peak heating.

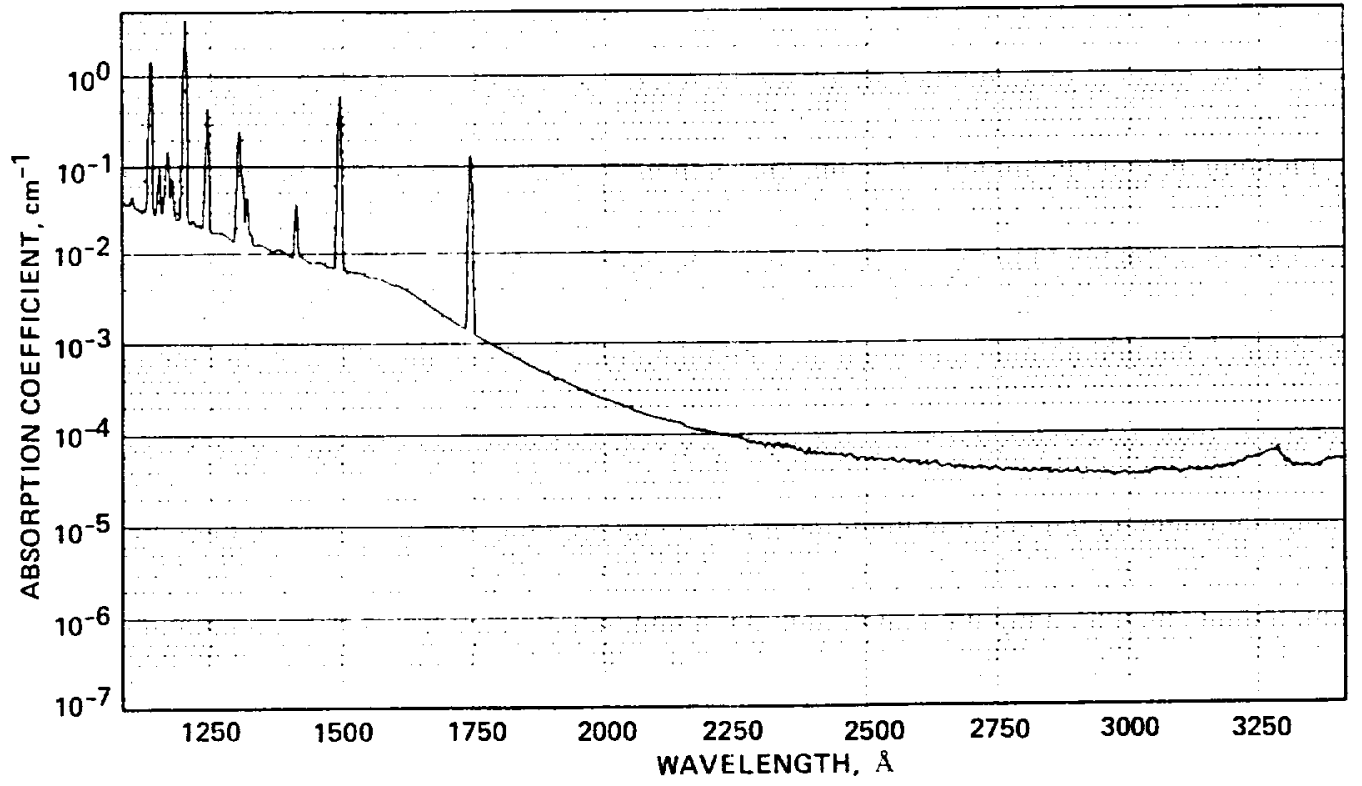

Figure 6.- Calculated absorption coefficient at a point on the AFE stagnation streamline. 
A. Allowed Transitions
1. $b^{1} \Sigma_{u}^{+}-x^{1} \Sigma_{g}^{+}$
First Birge - Hopfield
2. $b^{1} \Pi_{u}-x^{1} \Sigma_{g}^{+} \quad$ Second Birge - Hopfield

B. Forbidden Transitions
1. $A^{3} \Sigma_{u}^{+}-X^{1} \Sigma_{g}^{+} \quad$ Vegard-Kaplan
2. $B^{3} \Pi_{g}-X^{1} \Sigma_{g}^{+} \quad$ Wilkinson
3. $w^{3} \Delta_{u}-x^{1} \Sigma_{g}^{+}$Saum-Benesch
4. $B^{\prime}{ }^{3} \Sigma_{u}^{-}-X^{1} \Sigma_{g}^{+}$Ogawa-Tanaka-Wilkinson
5. $\quad a^{1} \Pi_{g}-X^{1} \Sigma_{g}^{+} \quad$ Lyman-Birge-Hopfield
6. $w^{1} \Delta_{u}-X^{1} \Sigma_{g}^{+} \quad$ Tanaka
7. $a^{1} \Sigma_{u}^{-}-X^{1} \Sigma_{g}^{+}$Ogawa-Tanaka-Wilkinson-Mullikan

Figure 7. $-\mathrm{N}_{2}$ band systems involving the ground state. 
For: Singie State $(\Sigma, \Pi$. د. etc.)

$\Delta \Lambda=0$

Hund's case (a)

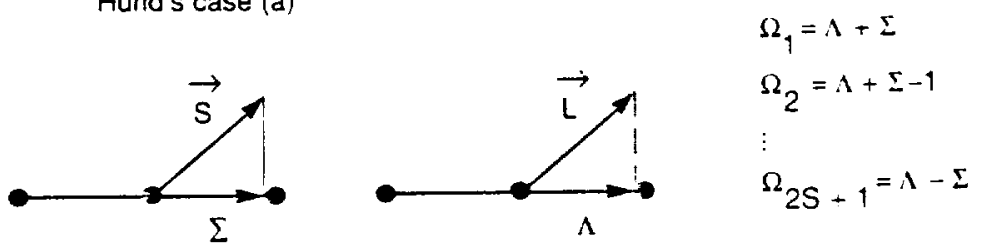

$H_{i j} \equiv H\left(A \Sigma_{i} \wedge \Sigma_{j}\right)=\left\langle\Delta S \Sigma_{i} j \Omega \Omega_{i} H J \Omega_{j} \wedge S \Sigma_{j}\right\rangle$

Spin - Orbit: $H^{\text {SO }}(\Lambda \Sigma ; \Lambda \Sigma)=A \Lambda \Sigma$

Spin - Spin: $H^{\text {SS }}\left(\Lambda \Sigma: \Lambda J=\varepsilon\left[3 \Sigma^{2}-S(S+1)\right]\right.$

Spin - Rotation: $H^{S r}(\Lambda \Sigma ; \Lambda I)=\gamma\left[\Sigma^{2}-S(S+i)\right]$

$$
H^{S r}(\Lambda \Sigma ; \Lambda \Sigma \pm 1)=-\frac{\gamma}{2}[S(S+1)-\Sigma(\Sigma \pm 1)]^{1 / 2}[J(J+1)-\Omega(\Omega \pm 1)]^{1 / 2}
$$

Rotational Energy and Distortion :

$H^{P}\left(\Lambda \Sigma_{i} ; \Lambda \Sigma_{j}\right)=B_{v} M-D_{v} M^{2}+H_{v} M^{3}+F_{v} M^{4}+\cdots$

Where:

$M(\Lambda \Sigma ; \Lambda \Sigma)=J(J+1)-\Omega^{2}+S(S+1)-\Sigma^{2}$

$M(\Lambda \Sigma ; \Lambda \Sigma \pm 1)=[S(S+1)-\Sigma(\Sigma \pm 1)]^{1 / 2}[J(J+1)-\Omega(\Omega \pm 1)]^{1 / 2}$

$M^{2}=M \cdot M$

$M^{3}=M^{2} \cdot M$

$M^{4}=M^{3} \cdot M$

(etc.)

Figure 8.- Hamiltonian matrix elements. 


$$
\begin{aligned}
& J_{e-f}(J)=C_{0} S_{1, F}^{2}+C_{1} S_{1}, F_{2}, F \sqrt{2 J(J+1)}
\end{aligned}
$$

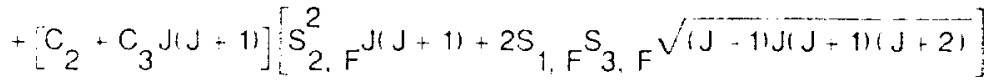

Where:

$F=1,2$ or 3 indicates spin substate

$s v_{e-f}^{F}=$ Lambda Doubling in F substate

$$
=E_{\varepsilon}^{F} \cdot E^{F}
$$

$\mathrm{S}_{\mathrm{i}, \mathrm{F}}=$ Matrix elements of the matrix

$S$ that diagonalizes the Hamiltonian Matrix

i. e. $E=S^{-1} H S$

Figure 9.- Perturbation expression for lambda splitting in triplet states (Dixon, 1959).

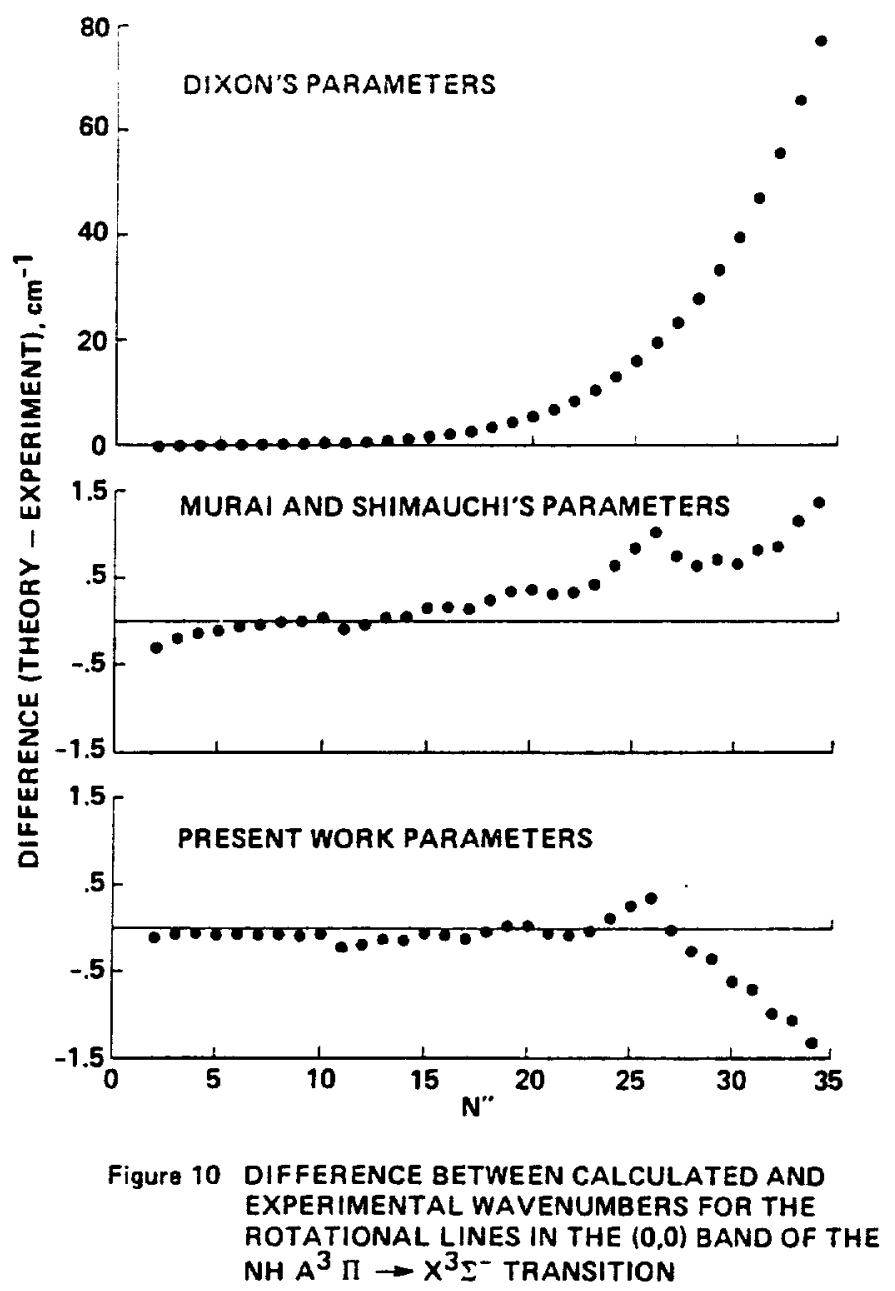

Figure 10.- Difference between calculated and experimental wavenumbers for the rotational lines in the $(0,0)$ band of the $A^{3} \Pi \rightarrow X^{3} \Sigma^{-}$transition in NH. Experimental data from Dixon $(1959)$. 


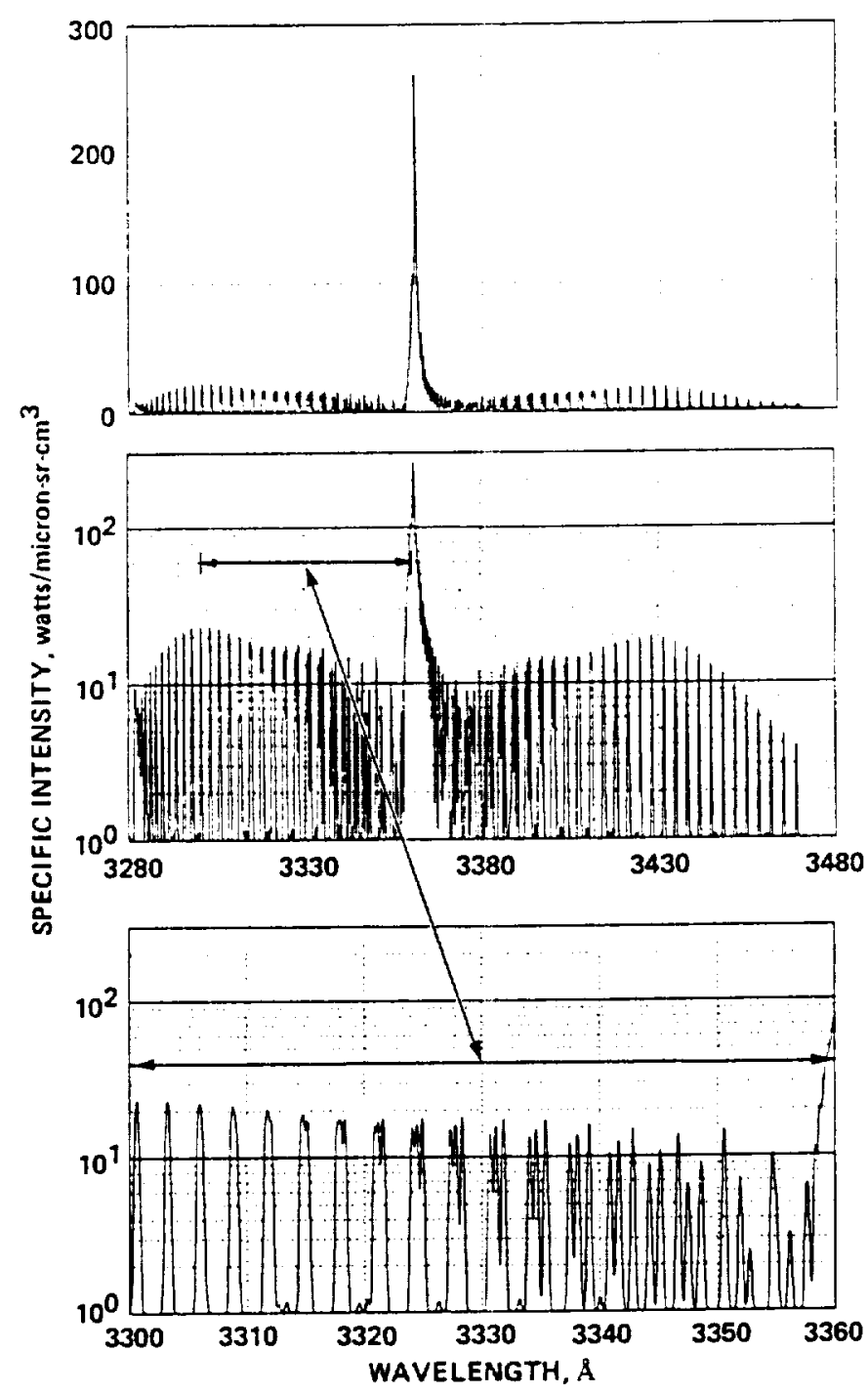

Figure 11 CALCULATED SPECTRUM OF THE (0.0) BAND OF THE $A^{3} \Pi \rightarrow x^{3} \Sigma^{-}$TRANSITION IN NH

Figure 11.- Calculated spectrum of the $(0,0)$ band of the $A^{3} \Pi \rightarrow X^{3} \Sigma^{-}$transition in $N H$, using parameters from present work. 


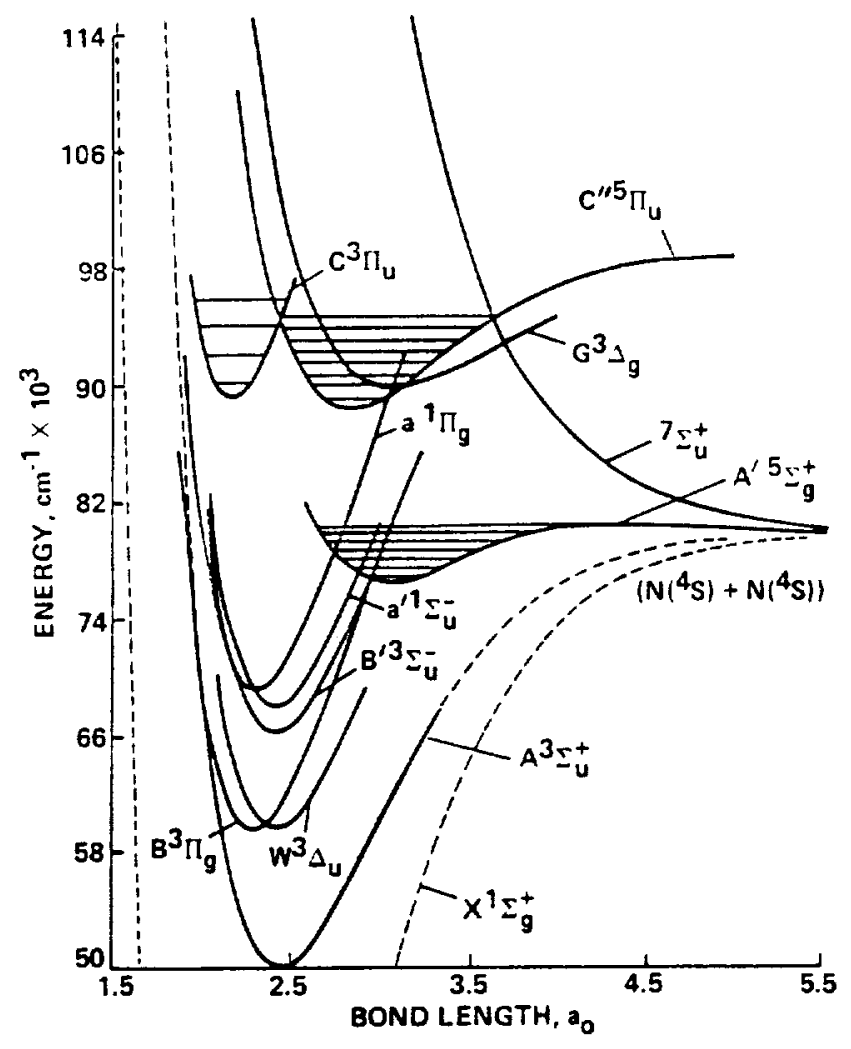

Figure 12.- Potential energy curves for $\mathrm{N}_{2}$ (Partridge et al., 1988). 


\begin{tabular}{|c|c|c|c|}
\hline \multicolumn{4}{|c|}{ Report Documentation Page } \\
\hline $\begin{array}{l}\text { 1. Report No. } \\
\text { NASA TM- } 101034\end{array}$ & 2. Government Accession No. & \multicolumn{2}{|c|}{ 3. Recipient's Catalog No. } \\
\hline \multicolumn{2}{|c|}{ 4. Titile and Subtitle } & \multicolumn{2}{|c|}{ October 1988} \\
\hline \multicolumn{2}{|c|}{$\begin{array}{l}\text { Recent Advances at NASA in Calculating the klectronic } \\
\text { Spectra of Diatomic Molecules }\end{array}$} & \multicolumn{2}{|c|}{ 6. Performing Organization Code } \\
\hline \multirow{2}{*}{\multicolumn{2}{|c|}{$\begin{array}{l}\text { 7. Authorls) } \\
\text { Ellis E. Whiting (ELORET Institute, Sunnyvale, CA } \\
\text { and John A. Paterson }\end{array}$}} & \multicolumn{2}{|c|}{$\begin{array}{l}\text { 8. Performing Organization Report No. } \\
\text { A-88297 }\end{array}$} \\
\hline & & \multicolumn{2}{|c|}{$\begin{array}{l}\text { 10. Work Unit No. } \\
583-01-11\end{array}$} \\
\hline \multicolumn{2}{|c|}{$\begin{array}{l}\text { Ames Research Center } \\
\text { Moffett Field, CA } 94035\end{array}$} & \multicolumn{2}{|c|}{ 11. Contract or Grant No. } \\
\hline \multirow{2}{*}{\multicolumn{2}{|c|}{$\begin{array}{l}\text { 12. Sponsoring Agency Name and Address } \\
\text { National Aeronautics and Space Administration } \\
\text { Washington, DC 20546-0001 }\end{array}$}} & \multicolumn{2}{|c|}{$\begin{array}{l}\text { 13. Type of Report and Period Covered } \\
\text { Technical Memorandum }\end{array}$} \\
\hline & & \multicolumn{2}{|c|}{ 14. Sponsoring Agency Code } \\
\hline \multicolumn{4}{|c|}{$\begin{array}{l}\text { 15. Supplementary Notes } \\
\text { Point of Contact: E11is E. Whiting, Ames Research Center, MS 230-3, } \\
\text { Moffett Field, CA } 94035 \text {, (415) } 694-4907 \text { or FTS } 464-4907 \\
\text { Paper presented at meeting on High Resolution Electronic Spectroscopy of Molecules } \\
\text { in Tihany, Hungary, on September } 19-24,1988 \text {. }\end{array}$} \\
\hline \multicolumn{4}{|c|}{$\begin{array}{l}\text { 16. Abstract } \\
\text { Advanced entry vehicles, such as the proposed Aero-assisted orbital Transfer } \\
\text { Vehicle, provide new and challenging problems for spectroscopy. Large portions of } \\
\text { the flow field about such vehicles will be characterized by chemical and thermal } \\
\text { nonequilibrium. Only by considering the actual overlap of the atomic and rota- } \\
\text { tional lines emitted by the species present can the impact of radiative transport } \\
\text { within the flow field be assessed correctly. To help make such an assessment, a } \\
\text { new computer program is described that can generate high-resolution, line-by-1ine } \\
\text { spectra for any spin-allowed transitions in diatomic molecules. The program } \\
\text { includes the matrix elements for the rotational energy and distortion to fourth } \\
\text { order; the spin-orbit, spin-spin, and spin-rotation interactions to first order; } \\
\text { and the lambda splitting by a perturbation calculation. An overview of the } \\
\text { Computational Chemistry Branch at Ames Research Center is also presented. }\end{array}$} \\
\hline \multicolumn{4}{|c|}{\begin{tabular}{l|r} 
17. Key Words (Suggested by Author(s)) & Unc \\
Diatomic & \\
Molecules & \\
High resolution spectra & \\
Aeroassist flight experiment &
\end{tabular}} \\
\hline $\begin{array}{l}\text { 19. Security Classif. (of this report) } \\
\text { Unclassified }\end{array}$ & $\begin{array}{l}\text { 20. Security Classif. (of this page) } \\
\text { Unc lassified }\end{array}$ & $\begin{array}{l}\text { 21. No. of pages } \\
25\end{array}$ & 22. Price $\mathrm{A02}$ \\
\hline
\end{tabular}


